\title{
Psychosocial Environmental Barriers to School Attendance among Children with Disabilities in Two Community Based Rehabilitation in Rwanda
}

\author{
Jean Baptiste Sagahutu ${ }^{*}$, Patricia Struthers ${ }^{2}$ \\ ${ }^{1}$ College of Medicine and Health Sciences, University of Rwanda, Kigali, Rwanda \\ ${ }^{2}$ School of Public Health, University of Western Cape, Cape Town, South Africa \\ Email: ${ }^{*}$ jeanbaptigol@gmail.com, ${ }^{*}$ jbsagahutu@khi.ac.rw
}

Received 25 December 2013; revised 20 January 2014; accepted 2 February 2014

Copyright (C) 2014 by authors and Scientific Research Publishing Inc.

This work is licensed under the Creative Commons Attribution International License (CC BY). http://creativecommons.org/licenses/by/4.0/

\section{(c) (i) Open Access}

\begin{abstract}
The purpose of this study was to determine the psychosocial environmental barriers to school attendance by children with disabilities in Rwanda. A quantitative, cross-sectional, descriptive study was conducted in one urban and one rural community-based rehabilitation centre. There was a sample of 94 parents or caregivers of children with disabilities who were not attending school. A structured closed-ended questionnaire was used. The Statistical Package for the Social Sciences (SPSS) (15.0 version) was used for data analysis. The data analysis included descriptive statistics as frequency distributions and percentages. The data were presented in the forms of cross-tables. CHI-Square was used to determine the association between variables. The level of significance (alpha) was set at 0.05. The findings indicate that in Rwanda there is a negative attitude among parents/caregivers and the community towards children with disabilities. Many parents/caregivers reported that having a child with a disability is a burden and shame in their families. A great proportion of parents/caregivers also indicated that, if they needed to make a choice, they would prioritise education for their child without the disability over their child with the disability. The majority reported the special school to be their first choice for their children with disabilities. others reported that the community gave their children different abusive names. About the teachers' attitude, a high proportion of parents/caregivers said that the teachers told them that their children had to go to the schools for other children with disabilities. Awareness creation and attitudinal change about disability issues are needed in Rwandese society to promote schooling for children with disabilities for the successful Education for All goals.
\end{abstract}

\footnotetext{
*Corresponding author.
}

How to cite this paper: Sagahutu, J. B., \& Struthers, P. (2014). Psychosocial Environmental Barriers to School Attendance among Children with Disabilities in Two Community Based Rehabilitation in Rwanda. Advances in Applied Sociology, 4, 149-155. http://dx.doi.org/10.4236/aasoci.2014.46019 
Keywords

Barriers, Children with Disabilities, Parents/Caregivers, Attitude

\section{Introduction}

Worldwide, disability prevalence increases as war, conflict, and poverty increase. However, the need of children with disabilities in developing countries is not well recognised (Shawky, Abalkhail, \& Soliman, 2002). In developing countries, fewer than $5 \%$ of children with disabilities reach the Education for All (EFA) goal of primary school completion (Richler, 2004).

Working to increase the number of children attending school this has become the objective of most governments in their effort to attain equity and harmony in their societies (Asprey \& Nach, 2006). The worldwide commitment to education for children with disabilities has been growing since 1975 (Smith-Davis, 2002). The world conference on Education for All: Meeting Basic Learning Needs (MBLN), held in Thailand 1990 was aimed at bringing the benefits of education to every citizen in every society. It comprised a broad coalition of national governments, civil society groups, and development agencies such as UNESCO and the World Bank (UNESCO, 1990). The World Summit for the children with disabilities, held in New York 1990, adopted the goal of Education for All by the year 2000 including LSEN (UNESCO, 1994).

Furthermore, the Salamanca Statement was produced in Salamanca (Spain) in 1994, where 92 governments and 25 international organisations met at the world conference on Special Needs Education. They agreed to a new statement on the Education of All children with disabilities, which called for inclusion to be the norm (UNESCO, 1994). The Salamanca Conference adopted a new framework that ordinary schools should accommodate all children with disabilities, regardless of their physical, intellectual, social, emotional, linguistic or other conditions. Children with disabilities should attend the usual neighbourhood school that would be attended if the child did not have a disability (UNESCO, 1994).

Despite these policy declarations and statements, UNESCO (2004) and Richler (2004) estimate that 98\% of children with disabilities in developing countries do not attend school and 99\% of girls with disabilities are illiterate.

Rwanda, a low income country located in central Africa, faces the same problem. Rwanda is a small country located in Sub-Saharan Africa in the great lakes region. It is a landlocked country bordered by Uganda to the north, Tanzania to the east, Burundi to the south and the Democratic Republic of Congo to the west. Its surface area is $26,338 \mathrm{~km}^{2}$ and it is Africa's most densely populated country with up to 467 people per km² (Rwanda Country Report, 2010). In Rwanda the educational opportunities for disabled children lie within some special schools and centres. There are a limited number of government special schools which are almost exclusively for children with visual and hearing difficulties (Handicap International, 2007). For the most part, educational provision for children with disabilities is organised outside of the national system by private and religious organisations (Handicap International, 2007). Most of those schools are located in urban areas far from most children with disabilities' homes, and their limited capacity cannot solve the needs of large numbers of children with disabilities.

In recent years a policy of inclusive education has been implemented in a number of schools around the country (Karangwa \& Kobusingye, 2008). Primary school is compulsory and the Government of Rwanda has implemented the policy of fee-free education to ensure attainment of the policy of universal primary education and Education for All by 2015. However, after working in Community Based Rehabilitation (CBR) for about four years in the eastern province of Rwanda, the researcher found that the majority of children with disabilities had never attended schools, and others start school but drop out after a short period of attendance. The aim of this study was to identify the psychosocial environmental barriers to school attendance by children with disabilities in Rwanda. In this paper, the term environmental psychosocial barriers are related to negative attitudes and perceptions of the community or family that may hinder the school attendance by children with disabilities.

\section{Methodology}

\subsection{Setting}

The study was carried out in the day centres of two Community-Based Rehabilitation (CBR) programmes in 
Rwanda: Inkurunziza CBR programme which is urban and Gahini CBR programme which is rural. These two settings were selected because of the large number of parents of children with disabilities who attended the programmes.

\subsection{Study Design}

This study was quantitative in nature using descriptive observational with cross-sectional study design. To determine the relationship between variables, the inference was also used in this study. The research assistants have been trained to collect data. The structured questionnaire with closed-ended questions has been distributed among parents or caregivers of children with disabilities who were not attending school. The data collection was done in the day centres of two Community Based Rehabilitation programmes (Inkurunziza and Gahini). Those who could not read and write the research assistants helped them to feel the questionnaires.

\subsection{Population and Sampling}

The total population of children with disabilities (CWDs) in the area or of those attending these centres was not known by the CBR workers. Accurate records were not available, in part, because some parents only bring their children once, so these records are not kept. A time limited sample, with data collected over 6 weeks, of 94 parents or caregivers of children with disabilities who were not attending school participated in the study. The sample included all parents or caregivers who had brought children with disabilities aged 7 - 18 years, who were not attending schools, to the centres during the period of data collection. This included also children who had attended school for a short period but had subsequently dropped out.

\subsection{Study Instrument}

A structured questionnaire with closed ended questions was developed by the researcher and his supervisor, based on literature and researcher's experience working at the centres, was used to collect data. The questionnaire was a non-standardised instrument because no standardised questionnaire that met the specific needs of this study could be found. The original questionnaire was in English and translated into Kinyarwanda, the local language spoken in Rwanda.

\subsection{Data Analysis}

The Statistical Package for the Social Sciences (SPSS) (15.0 version) was used for data analysis. Based on the descriptive nature of the study, the data analysis included descriptive statistics as frequency distributions and percentages. The data was presented in the forms of cross-tables. CHI-Square was used to determine the association between variables. The level of significance (alpha) was set at 0.05 .

\subsection{Ethics}

Ethical permission to carry out the study was obtained from all the institutions involved. All participants completed consent forms after reading an information sheet on the study, or having had it read to them. Participation in the study was voluntary, and the participants were free to withdraw from the study at any time. Respect, confidentiality and anonymity were ensured.

\section{Results}

Of the 94 participants $57.1 \%(n=28)$ of male children and 57.8\% $(n=26)$ of female children had never attended school while $42.9 \%(n=21)$ of the male children and $42.2 \%(n=19)$ of female children had dropped out of school. This indicates that 54 children with disabilities did not attend school while 40 children dropped out.

Table 1 compares the attitudes of parents/caregivers in rural and urban areas towards children with disabilities.

Table 2 also compares the attitudes of parents/caregivers towards children with disabilities with school attendance. The CHI-Square test found a significant association between the preferred special school and never attending school $(P$-value $=0.002)$.

Table 3 compares the perception of the parents/caregivers of the community's attitudes to their children and other people with disabilities with school attendance. 
Table 1. Attitude of parents/caregivers towards children with disabilities versus residence $(n=94)$.

\begin{tabular}{|c|c|c|c|}
\hline & Rural $(n=49)$ & Urban $(n=45)$ & Total $(n=94)$ \\
\hline Attitude towards children with disabilities & n (\%) & n (\%) & n (\%) \\
\hline Having a child with disability is a shame to the family & $27(55.1)$ & $30(66.7)$ & $57(60.6)$ \\
\hline Having a child with a disability is a burden & $41(83.7)$ & $31(68.9)$ & $72(76.6)$ \\
\hline I am proud of the child with a disability & $8(16.3)$ & $7(15.6)$ & $15(16)$ \\
\hline I prefer the child with disability to go to school & $23(46.9)$ & $10(22.2)$ & $33(35.1)$ \\
\hline I prefer the child without disability to go to school & $26(53.1)$ & $35(77.8)$ & $61(64.9)$ \\
\hline I prefer my child with disability to go to special school & $42(85.7)$ & $37(82.2)$ & $79(84)$ \\
\hline I prefer my child with disability to go ordinary school & 7 (14.3) & $8(17.8)$ & $15(16)$ \\
\hline
\end{tabular}

Table 2. Attitude towards children with disabilities versus school attendance $(n=94)$.

\begin{tabular}{cccc}
\hline Attitude towards children with disabilities & $\begin{array}{c}\text { Never attended } \\
\text { school (n= 54) }\end{array}$ & $\begin{array}{c}\text { Started school with } \\
\text { disability (n= 30) }\end{array}$ & $\begin{array}{c}\text { Dropped out after } \\
\text { acquiring disability (n = 10) }\end{array}$ \\
\hline n (\%) \\
Having a child with disabilities is a shame to the family & $36(66.7)$ & $16(53.3)$ & $5(50)$ \\
Having a child with disability is a burden & $43(79.6)$ & $21(70)$ & $8(80)$ \\
I am proud of the child with a disability & $8(14.8)$ & $5(16.7)$ & $2(20)$ \\
I prefer the child with disability to go to school & $15(27.8)$ & $15(43.3)$ & $6(60)$ \\
I prefer the child without disability to go to school & $39(72.2)$ & $17(56.7)$ & $8(40)$ \\
I prefer my child with disability to go to special school & $49(90.7)^{*}$ & $22(73.3)$ & $2(20)$ \\
I prefer my child with disability to go ordinary school & $5(9.3)$ & $8(26.7)$ & \\
\hline
\end{tabular}

Table 3. The relationship between the perception of the parents/caregivers of the community's attitudes to disability versus children's school attendance $(\mathrm{n}=90)($ Missing $=4)$.

\begin{tabular}{|c|c|c|c|c|}
\hline Perception & $\begin{array}{c}\text { Never attended } \\
\text { school }(n=53) \\
n(\%)\end{array}$ & $\begin{array}{l}\text { Started school } \\
\text { with disability } \\
(n=28) n(\%)\end{array}$ & $\begin{array}{l}\text { Dropped out after } \\
\text { acquiring disability } \\
(n=9) n(\%)\end{array}$ & $\begin{array}{c}\text { Total } \\
(\mathbf{n}=90) \\
\mathbf{n}(\%)\end{array}$ \\
\hline $\begin{array}{l}\text { The Department of Education has not made it possible for } \\
\text { my child to go to school because he/she has a disability }\end{array}$ & $38(71.7)$ & $19(67.9)$ & $6(66.7)$ & $63(70)$ \\
\hline Other children in my community don't want to play with my child & $25(47.2)$ & $11(39.3)$ & $2(22.2)$ & $38(42.2)$ \\
\hline The community considers my child as a shame in my family & $30(56.6)$ & $14(50)$ & $6(66.7)$ & $50(55.6)$ \\
\hline They call my child different names because of his/her disability & $40(75.5)$ & $18(64.3)$ & $7(77.8)$ & $65(72.2)$ \\
\hline My child is hidden because people laugh to him/her & $10(18.7)$ & $4(14.3)$ & 0 & $14(15.6)$ \\
\hline $\begin{array}{l}\text { Other people do not want my child to attend } \\
\text { church because he/she is disabled }\end{array}$ & $14(26.4)$ & $6(21.4)$ & $4(44.4)$ & $24(26.7)$ \\
\hline It is difficult for disabled girls to get married & $39(73.6)$ & $23(82.1)$ & 7 (77.8) & 69 (76.7) \\
\hline It is difficult for disabled people to get a job & 36 (67.9) & 19 (67.9) & $5(55.6)$ & $60(66.7)$ \\
\hline
\end{tabular}

\section{Discussion}

\subsection{Attitudes of Parents and Caregivers towards Children with Disabilities}

According to Wolfensohn (2004), the greatest barriers to school attendance by children with disabilities are caused by society, not by particular medical impairments. This study highlights a number of the negative attitudes reported by parents and caregivers which can hinder the school attendance by children with disabilities in Rwanda.

\subsubsection{Inability to Learn}

This study compared the attitudes of parents/caregivers in rural and urban areas towards having children with 
disabilities. The majority of parents/caregivers $(64.9 \%, \mathrm{n}=61)$ indicated that, if they needed to make a choice, they would prioritise education for their child without the disability over their child with the disability. A barrier to sending their child to school was the belief that the child was unable to learn. In Rwanda, people with disabilities are often considered as people without intelligence and not able to be educated (Thomas, 2008).

The comparison of attitudes of parents/caregivers towards children with disabilities in relation to school attendance indicates that the majority of parents/caregivers who preferred the children without disabilities to have a priority to go to school were those whose children never attended school $(72.2 \%$; $n=39)$. Many parents/caregivers in poor communities prefer their children without disabilities to go to school rather than those with disabilities (Ahuja, 2000). They may not want to prioritise their education saying that the children are incapable of learning, and will not contribute to the society as $66.7 \%(n=60)$ of parents/caregivers reported that it is difficult for disabled people to get a job, where the majority of them $(67.9 \% ; n=36)$ were those their children have never attended school.

\subsubsection{Choice of School Special versus Ordinary Schools}

This study also indicates the kind of school reported by parents/caregivers to be their choice for their children with disabilities. There are two types of schools which can accommodate children with disabilities: ordinary schools and special schools. According to Every Child Matters (2005), special schools make special educational provision for children with special educational needs (SEN) whose needs cannot be fully met within mainstream provision. Ordinary schools are the nearest schools that accommodate children with and without disabilities (UNESCO, 2002).

According to the residence, the majority of parents/caregivers $(84 \% ; n=79)$ reported the special school to be their first choice for their children with disabilities. This number is slightly higher in the rural area $(85.7 \% ; \mathrm{n}=$ $42)$ than the urban area $(82.2 \% ; n=37)$. According to the school attendance, the majority $(90.7 \% ; n=49)$ who reported the special schools to be their choice, they were parents/caregivers of children who never attended school. This shows that many parents prefer their children to be in a special school rather than in the ordinary schools. According to Karangwa and Kobusingye (2008), Handicap International (Rwanda) in conjunction with the Rwandan Ministry of Education have started inclusive education in a number of schools around the country for ensuring that children with disabilities have access to education. This is a new policy in Rwanda, but many parents are not yet aware that they can send their children with disabilities to ordinary schools.

The goal of Education for All cannot be met if parents/caregivers want their children to be in those special schools which cannot accommodate all or meet the need of all children with disabilities. According to Thomas (2005), the special schools accommodate a small number of children with disabilities compared to ordinary schools and they cannot be found in every child's community. This might be a barrier to school attendance by a large number of children with disabilities as almost all of those who never attended school preferred the special school to be their choice. The CHI-Square test found a significant association between preferring special school and never attending school. This means that the parents/caregivers of children who never attended school preferred more special schools than ordinary schools. As stated by UNESCO (2002), ordinary schools would be the most preferred by parents of children with disabilities because they are the nearest schools that accommodate children with and without disabilities.

\subsubsection{Burden}

In Rwanda, when a person becomes disabled or a disabled child is born, the family enters into a new world about which they know next to nothing and about which they have a lot of stereotyped notions (Republic of Rwanda, 2005). The findings of this study indicate that the negative attitude towards children with disabilities was very pronounced among parents/caregivers. According to the comparison of the attitudes of parents/caregivers in rural and urban areas towards children with a disabilities in their families, $76.6 \%(n=72)$ of parents/caregivers found having a child with a disability a burden. This included both rural and urban areas. However, the percentage was higher in the rural area $(83.7 \%$; $=41)$ than the urban area $(68.9 \%$; $n=31)$. This might be the result of lower level of education and high level of poverty in the rural area. Rwanda is one of the poorest countries in the world especially in rural communities. The Poverty Reduction Strategy Paper (PRSP) quotes economic and historical factors influencing the widespread poverty (Republic of Rwanda, 2007). The real GDP growth was 6.5\% in 2010 (Rwanda Country Report, 2010). 


\subsubsection{Shame}

Although a small percentage of parents/caregivers in both rural $(16.3 \% ; n=8)$ and urban $(15.6 \% ; n=7)$ areas reported being proud of having a child with a disability, a very common negative statement was that the child was considered to be a shame in the family $(60.6 \% ; n=57)$. These findings indicate that more participants in the urban area $(66.7 \% ; n=30)$ than in the rural area $(55.1 \% ; n=27)$ felt the disability was a shame for the family. It was mentioned by a greater proportion of participants whose children had never attended school $(66.7 \%$; $n=36)$ than those who had received some schooling (50\% - 53.3\%). This suggests that shame was a barrier to children with disabilities attending school. However, the children who never attended school may have been more severely disabled than those who had some experience of school and the shame may have been related to the severity of disability. It is also possible that the experience of having the child attend school for a period of time had reduced the sense of shame in the family.

Thomas (2005: p. 21) states that in Rwanda children with disabilities are considered as a source of shame in a family, underestimated, being-seen as useless, meaningless, and there is an assumption "when you are a disabled person, you live with your disabilities and wait for what God will do for you” (Thomas, 2005: p. 21). Furthermore, in Rwanda people with disabilities are usually identified as among the most vulnerable groups and, sometimes, disability is seen as a curse or punishment from God (FIDIDA, 2008). This can result in shame in the family. The problem of shame has been reported elsewhere. Wolfensohn (2004) states that, as a result of shame, many families tend to hide their children if they have a disability and not to offer them any opportunities for development due to both fear for and being ashamed of them.

\subsection{Perception of the Parents/Caregivers of the Community's Attitudes to Disability versus Children's School Attendance}

The findings of this study indicate that the majority of parents/caregivers $(76.7 \% ; n=69)$ believe that the community thinks it is difficult for disabled girls to get married. This proportion was very high $(82.1 \% ; n=23)$ among parents/caregivers whose children started going to school with a disability. This could restrict the school attendance of children with disabilities, especially girls, for the reason that they will not play a role in family in terms of love and getting married. According to UN Millennium Development Goals (2007), the girls with disabilities are the most marginalised and least likely to be educated, as they have double disadvantages compared to boys including their gender and disability, and Thomas (2005) argues that, in Rwanda, disabled women find it difficult to get married.

Calling children with disabilities abusive names demonstrates a common negative attitude towards children with disabilities in the community $(72.2 \% ; n=65)$. The negative attitudes to school attendance by children with disabilities extend to the relatives and community in large, and finally to the other children who abuse children with disabilities by giving them different unkind names (UNESCO, 2007). Children in Rwanda are given different abusive names relating to their impairment or their difficulties. Some of those names indicate that they are useless, different from normal people, etc. Among those abusive names in Kinyarwanda include "karema" or "kajoliti" (casualty). This might contribute to the decision not to send the child to school because many parents/ caregivers $(75.5 \%$; $n=40)$ whose children were given abusive names did not send their chidden to school. This kind of bullying needs to be stopped in the Rwandan community because it negatively affects children with disabilities participating in different activities as well as education.

\section{Conclusion and Recommendations}

This study is the first to identify the psychosocial environmental barriers to school attendance by children with disabilities in Rwanda. The attitude among parents/caregivers and the community at large found negative towards children with disabilities. Awareness creation and attitudinal change about disability issue among Rwandese society are needed to promote schooling for children with disabilities. Although the international policy of inclusive education is being implemented in Rwanda, many children with disabilities are still out of school. A successful Education for All would be possible if it were focused on removal of all barriers which can hinder the education process or school attendance of children with disabilities.

To change the parent's self esteem so that they do not feel shame to having a child with a disability, a comprehensive CBR programmes should help the community to create the awareness of having a child with a disability. This may be done by education and empowering the parents/caregivers of children with disabilities. 
The Ministry of Gender and Family Promotion must play a greatest role in creating awareness in Rwandan community towards girls with disabilities and in empowering their families.

For successful Education for All, the Rwandan Department of Education should train the primary school teachers in order to accommodate children with disabilities in ordinary schools.

\section{Acknowledgements}

This work was made possible through the financial support of the Government of Rwanda, through the Ministry of Education. Above all, we are grateful to all the parents and caregivers of children with disabilities who participated in this study. Finally, we thank the Inkurunziza and Gahini CBR progarammes and all community-based rehabilitation workers who assisted during research field work.

\section{Conflicts of Interest}

The authors declare that there is none.

\section{Authors' Contributions}

J. B. Sagahutu conceptualised the study and supervised data collection. He has participated in the study design, the interpretation of data and drafting of manuscript. P. Struthers supervised the overall work and participated in drafting of manuscript.

\section{References}

Ahuja, A. (2000). Overcoming Barriers to Learning in Developing Countries. Manchester: University of Manchester.

Asprey, N. (2006). The Importance of Awareness and Communication for the Inclusion of Young People with Life Limiting and Life Threatening Conditions in Mainstream Schools and Colleges. British Journal of Special Education, 33, $10-11$. http://dx.doi.org/10.1111/j.1467-8578.2006.00406.x

Finishing Disabled People’s International Development Association (FIDIDA) (2008). Disability and Development. Helsinki.

Handicap International (2007). Our Work with Special School and Centres in Rwanda. Kigali: Handicap International.

Karangwa, E., \& Kobusingye, M. (2008). Report of the Survey Carried Out in Schools Developing towards Inclusive Education. Kigali: Handicap International.

Ministry of Education (MINEDUC) (2003). Education Sector Strategic Plan. Kigali: Author.

Republic of Rwanda (2005). National Employment Policy. Kigali.

Richler, D. (2004).Quality Education for Persons with Disabilities. Background Paper Presented for the Education for All Global Monitoring Report. Paris: UNESCO.

Rwanda Country Report (2010). GDP Data and GDP Forecasts; Economic, Financial and Trade Information; the Best Banks in Rwanda; Country and Population Overview. Kigali.

Shawky, S., Abalkhail, B., \& Soliman, N. (2002). An Epidemiological Study of Childhood Disability in Jeddah, Saudi Arabia. Paediatric and Perinatal Epidemiology, 16, 61-65. http://dx.doi.org/10.1046/j.1365-3016.2002.00365.x

Smith, D. (2002). Rehabilitation. The Use of Theories and Models in Practice. Cambridge: University Press.

Thomas, P. (2005). Mainstreaming Disability in Development: Country-Level Research. Rwanda Country Report. Executive Summary. Kigali.

Thomas, C. (2008). Disability: Getting It “Right”. Journal of Medical Ethics, 34, 15-17. http://dx.doi.org/10.1136/jme.2006.019943

UN Millennium Development Goals (2007). Access to Basic Services for the Poor: The Importance of Good Governance. New York: UNDP.

UNESCO (1990). Framework for Action: Meeting Basic Learning Needs. Paris: UNESCO

UNESCO (1994). The Salamanca Statement and Framework for Action on Special Needs Education. Paris: UNESCO.

UNESCO (2002). Inclusive Education: Definition, Principles and Implementations. Conference of the Ministers of Education of African Member States (MINEDAF VIII), Dar-es-Salam, 2-6 December 2002.

UNESCO (2004). Who Are Excluded and Why? Education for All Week. Paris: UNESCO.

UNESCO (2007). Barriers to Inclusive Education. Paris: UNESCO.

Wolfensohn, J. D. (2004). Disability and Inclusive Development: Latin America and the Caribbean. Washington: World Bank. 
Scientific Research Publishing (SCIRP) is one of the largest Open Access journal publishers. It is currently publishing more than 200 open access, online, peer-reviewed journals covering a wide range of academic disciplines. SCIRP serves the worldwide academic communities and contributes to the progress and application of science with its publication.

Other selected journals from SCIRP are listed as below. Submit your manuscript to us via either submit@scirp.org or Online Submission Portal.
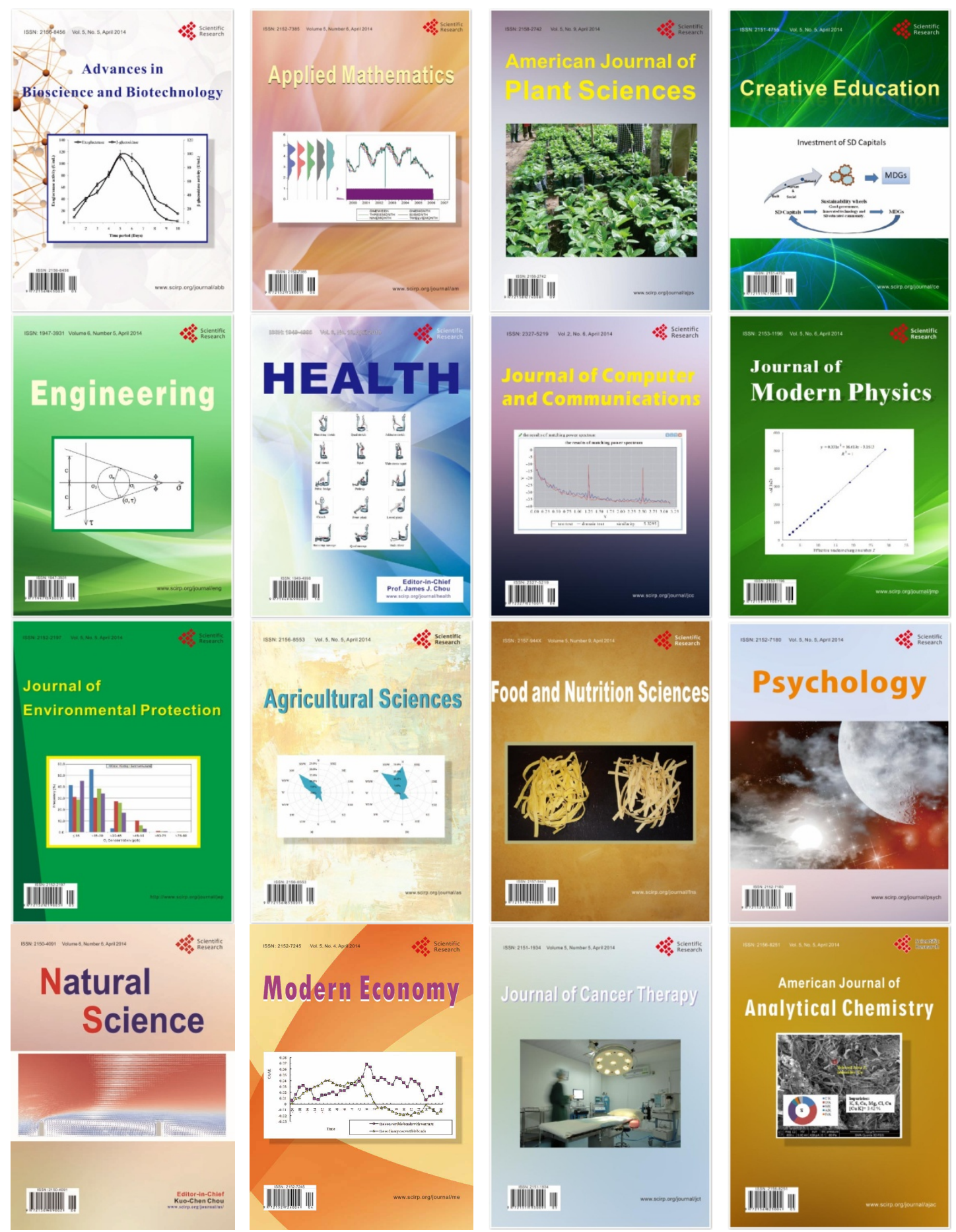